\title{
Vibration Characteristics Analysis of Exhaust System Based on Optimization of Hanger Position

\author{
GONGYu Pan ${ }^{1,}$, DANQingCao ${ }^{2, b}$
}

${ }^{1}$ School of Vehicle and traffic engineering ,Jiangsu University,Zhenjiang Xuefu Road No. 301, Jiangsu,China

${ }^{2}$ Full address of second author, including countrySchool of Vehicle and traffic engineering ,Jiangsu University,Zhenjiang Xuefu Road No. 301, Jiangsu,China

a476978072@qq.com, bcaodq101@126.com

Keywords:Exhaust system; Free modes; Restrained modes; Optimization of the locations of hangers; Reaction forces ofhangers

Abstract.To improve the performance of one exhaust system, in the article, a exhaust system in the market was conducted by the stress analysis and optimization of the hanger. Firstly, the 3D model was built by Catia and a FEM model was built by Hypermesh, and then the calculation of the free modes were done by Anasys. After that, with the method of component mode synthesis and then through the analysis by the software Nastran, the best hanger position was got. Finally, the optimized system was conducted the restrained modes analysis, and the reaction force of hanger was calculated as well,by verification and comparison, the modal mode of vibration is more appropriate, and the peak of the force has decreased, in the low frequency section, the curve is more smooth,the optimization was proved to be effective to improve the system's NVH performance.

\section{Introduction}

Exhaust system needs to be paid attention to the following three aspects: (1)The first mode of bending and torsion modal shape should be noticed (2) Free modal inherent frequency should be away from engine idle ignition frequency (3) Under the engine vibration, hanging point force peak should not be greater than the target value.

As the main vibration excitation source, Powertrain transmit the vibration to the exhaust system, and then transmit it to the body through the hanging lug, if the lug position and its performance matching is not good, it will lead to the vibrations of various parts of the body, and will affect the comfort of the passengers. Therefore, the layout of the hanging lug is an important part of the design of exhaust system.

\section{Exhaust system model}

\section{The geometry of exhaust system}

In this paper, a simplified model is established with CATIA of the manufacturer's drawings, including the catalytic converter, the front and rear muffler, the exhaust gas turbine, the catalytic converter, and the hanging lug. In the simplified model, the catalytic converter, the

brackets were ignored. The small impacts of the exhaust system on the mechanical structure were ignored as well. The rams, the holes, as well as the screw nuts and some unimportant parts are also ignored. 


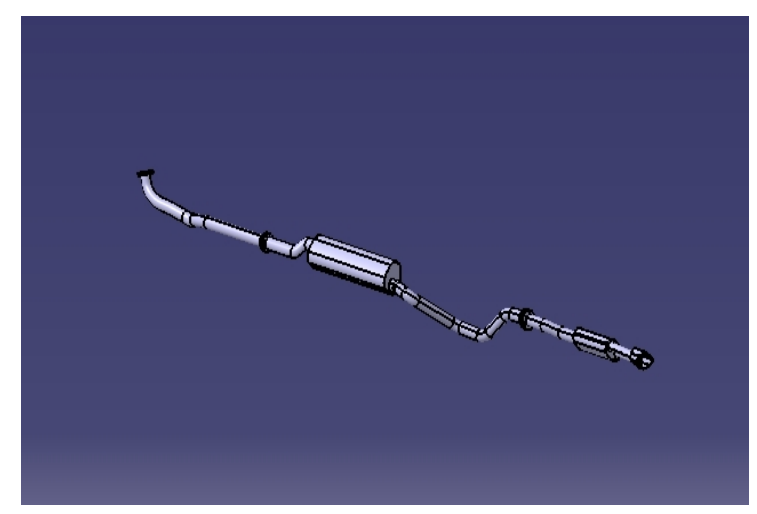

Figure 1.The $3 \mathrm{~d}$ model.

\section{The finite model}

In the finite elements model, the shell element is used in the pipe and the muffler, and the method is used during dealing it, which the mass point is to replace mass, then giving them the information about the concentration of mass and the moment of inertia. The position of the concentrated mass point is generally located in the center of mass, and the connecting pipe is connected with the connecting pipe by RBE2 rigid unit. There is also a layer of heat shield on the catalytic converter, and there are small holes in the heat shield, they are useless in the whole analysis, so they are ignored as well.

The method when simplifying the corrugated pipe is to use a spring element and two mass points to replace it, the spring stiffness is got by the experimental test, the quality of the two focus points are got by measuring the quality of the corrugated pipe, the corrugated pipe connects with the exhaust pipes in RBE2 rigid unit. After dividing each part, the RBE2 rigid element is used to connect each part, and the welding connections between different departments are simulated by REB2 as well [1]. Figure 2 shows the finite element model after the division.

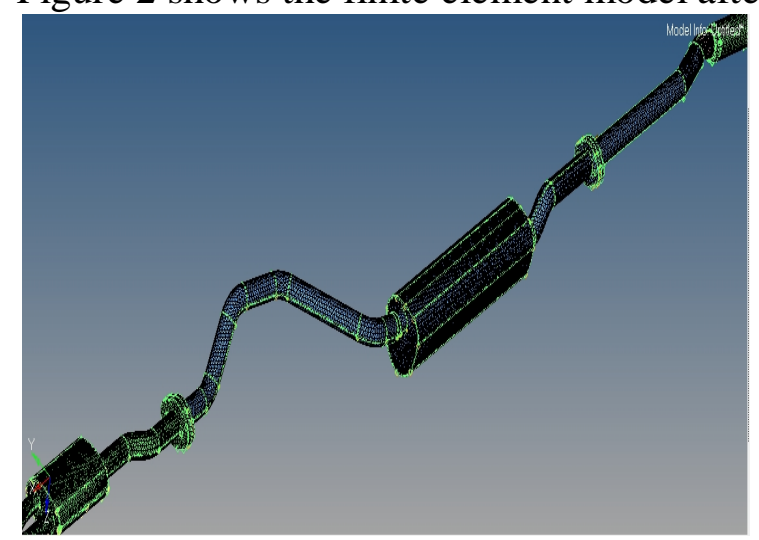

Figure 2. The finite elements model.

\section{The Free Modal Calculation}

The modal analysis is the key to the analysis of the exhaust system. The modes of the exhaust system must be separated from the vibration frequencies of the engine and the vehicle body. Otherwise, once the vibration frequencies are coupled, it will produce a stronger vibration.

The idle speed of engine is around the 650 rounds each minute. For the four cylinders engines, the firing frequency should be greater than $20 \mathrm{~Hz}$, because the modes that are less than $20 \mathrm{~Hz}$ are the rigid modes, it is difficult to be excited, so they are not into consideration. In the design of the exhaust system, the lower mode density it has, the better performance the exhaust system it has. So, after calculation, there are in total 8 modes of the exhaust system in the range of $20 \sim 200 \mathrm{~Hz}$. 
Table1. Natural frequency of the free modes.

\begin{tabular}{|c|c|c|c|}
\hline Mode & $\begin{array}{c}\text { Frequency } \\
/ \mathbf{H z}\end{array}$ & Mode & $\begin{array}{c}\text { Frequency } \\
\mathbf{/ H z}\end{array}$ \\
\hline 1 & 0 & 10 & 52.72 \\
\hline 2 & 0 & 11 & 82.33 \\
\hline 3 & 0 & 12 & 108.95 \\
\hline 4 & 0.0019 & 13 & 120.39 \\
\hline 5 & 0.0025 & 14 & 170.37 \\
\hline 6 & 0.0063 & 15 & 174.20 \\
\hline 7 & 18.37 & 16 & 211.62 \\
\hline 8 & 23.18 & & \\
\hline 9 & 47.97 & & \\
\hline
\end{tabular}

As mentioned above, the idle speed is between 650-900r/min, the corresponding ignition frequency is $21.7-30 \mathrm{~Hz}$. From the table 2 can be seen, the exhaust system has avoided the idling frequency. According to the data provided by company, it just should be considered the vibration frequency of the engine around $21.7 \mathrm{~Hz}$ and $100 \mathrm{~Hz}$, which is possible to make the exhaust system resonance, so that the vibration mode can be considered in the case of the position of the exhaust hook. The vibration mode figures are as follows:

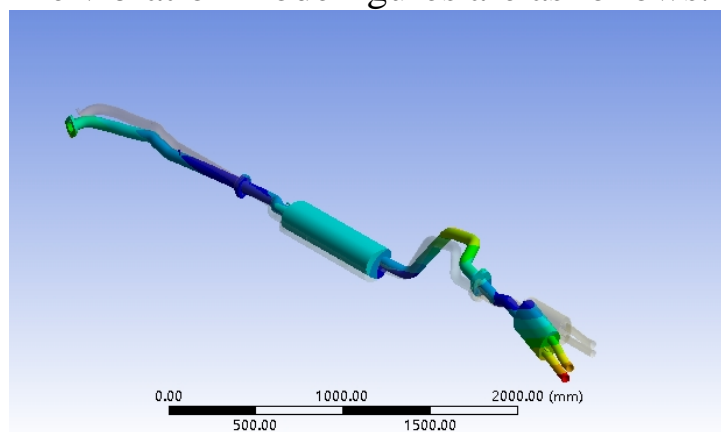

Figure 3 The $8^{\text {th }}$ mode of the free modal

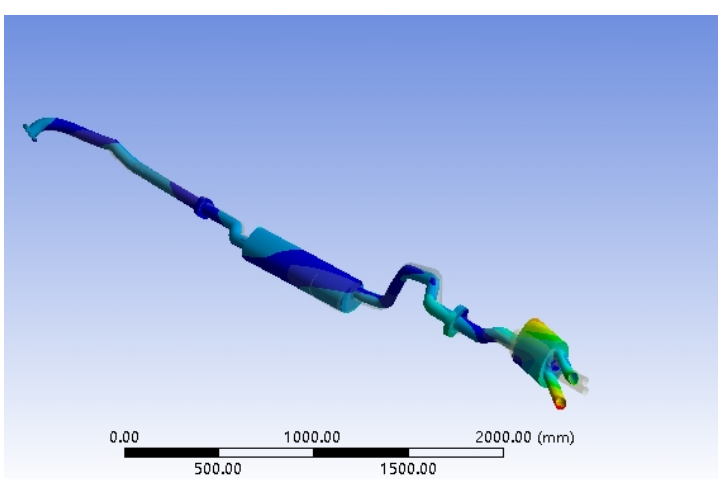

Figure 4 The $16^{\text {th }}$ mode of the free modal

At low frequency section, the displacement of the first flange, the rear pipe and the muffer is relatively greater, and the displacement of the rear muffer and rear pipe under the high frequency is big. So when arranging the position of the suspensions, the vibration of the different modes should be considered comprehensively, the position of the weighted sum of the vibration displacement should be smaller.

\section{The arrangement of hanger lug}

Because of the engine vibration and exhaust excitation, the vibration of the exhaust system will be transmitted to the body, which will increase the vibration of the body and increase the noise level of the vehicle. The location of the suspension is directly influenced the vibration of the exhaust system. Therefore, it is one of the key points for the design of the exhaust system to reasonably arrange the suspension point. 
After getting the results of the free modal, then the optimization of the positions of the hanger lug is carried. In Nastran, the method of the comprehensive modal nodes to obtain a continuous $\mathrm{Z}$ numerical table was used. The $\mathrm{Z}$ features are normalized to the feature vector and the smaller point is the potential lifting lug.

\section{Integrated modal node method}

This method only analyzes the position of the suspension point from the point of view of modal vibration mode. It is not the only method to determine the position of the lug. In this method, the vertical vibration of the exhaust system is the most influential to the body vibration and vehicle noise. In this paper, the coordinates of the $\mathrm{X}$ direction are from the front to the rear of the car, the $\mathrm{Y}$ coordinates are from the driver to the passenger's direction, the $\mathrm{Z}$ coordinates from the bottom to the top.

The theoretical basis is, for the exhaust system, a certain point normalizes $\mathrm{Z}$ direction of the vibration displacement the $\mathrm{Ai}$, in the frequency range of interest. If the exhaust system has $\mathrm{m}$ level modes, then the $\mathrm{Z}$ generalized vibration displacement is

$$
\text { As }=\sum\left(A_{\mathrm{i}}\right)^{2} \quad(\mathrm{i}=1,2, \cdots, \mathrm{m})
$$

In the design of the suspension point position of the exhaust system, the optimum suspension point is given by the minimum of Ai value.

\section{The lug position optimization}

In $\mathrm{Z}$ axis, the output point sequence is selected from the $\mathrm{X}$ axis of the exhaust system to the upper surface by NASTRAN, and the output point beginning is 1 , the gap is $1 \mathrm{~mm}$, the gap of two nodes is approximately $100 \mathrm{~mm}$, and the output points are selected to be the point sequences.

Then finding out square of the $\mathrm{Z}$ eigenvector, and then divided by the number that is maximum value of the square of $\mathrm{Z}$ axis to do the normalization. The $\mathrm{Zs}$ is the sum of the squares of the $\mathrm{Z}$ axis feature vector after the normalization. In Excel, output sequences in ascending, as figure5, after getting the corresponding points of $\mathrm{Z}$ axis feature vector, comparing the sum of the squares $\mathrm{Zs}$ ', in the curve of the wave, the lowest is installed with an exhaust system suspension point position. As shown in Figure 5, the nodes are 4, 21, 28, 35, 43, 47 and 53.

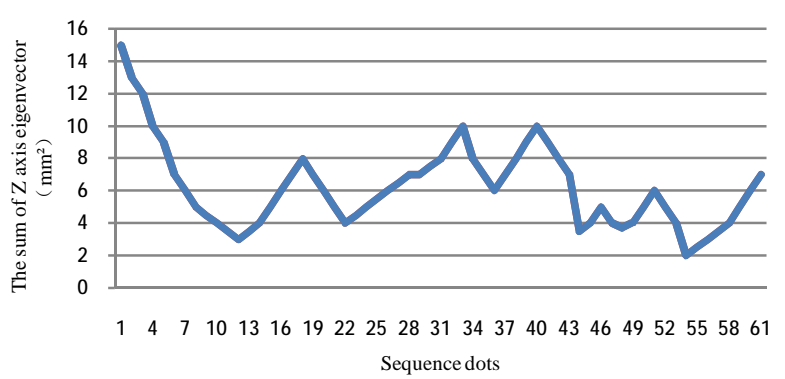

Figure 5 Potential lug positions

Lug position is not only to consider this aspect, but also needs to consider the interference and other issues. Because the point 11 is located in the corrugated pipe, so selecting the $21,28,35,43,47,53$ as the hanging point. The following diagram shows a schematic diagram of the improved hanging ear position. 


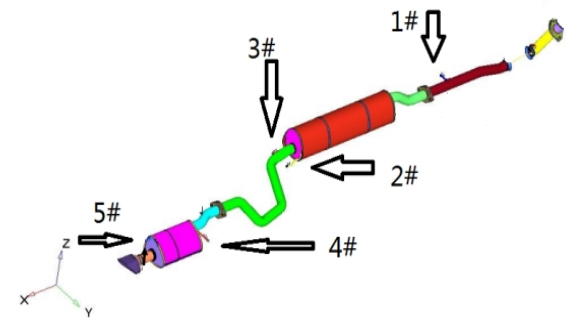

Figure 6 Schematic figure of hanging positions

\section{Restrained modal analysis}

After the work of arranging hanging ear position, compared with the free modal analysis, firstly seeing whether the system avoid the idle speed and the economic speed frequency. Idle speed is $650 \mathrm{r} / \mathrm{min}$, the economic speed is $3000 \mathrm{r} / \mathrm{min}$, the excitation frequency is $21.7 \mathrm{~Hz}$ and $100 \mathrm{~Hz}$. Analysis of the constraint mode results are shown in Table2.

Table 2Natural frequency of the restrained modes

\begin{tabular}{|c|c|c|c|}
\hline Mode & $\begin{array}{c}\text { Frequency } \\
/ \mathbf{H z}\end{array}$ & Mode & $\begin{array}{c}\text { Frenquancy } \\
/ \mathbf{H z}\end{array}$ \\
\hline 1 & 4.65 & 9 & 60.06 \\
\hline 2 & 5.12 & 10 & 64.09 \\
\hline 3 & 9.21 & 11 & 83.68 \\
\hline 4 & 14.00 & 12 & 88.55 \\
\hline 5 & 16.95 & 13 & 113.70 \\
\hline 6 & 18.70 & 14 & 117.40 \\
\hline 7 & 32.75 & 15 & 143.00 \\
\hline 8 & 35.72 & 16 & 192.80 \\
\hline
\end{tabular}

According to the above table, we can see that after the exhaust system added the hanging lug avoided the vibration frequency of the engine, and the optimization is basically effective.

Compared with the former model, the new arranged exhaust system has the retrained modal vibration figures which lead to less displacement.

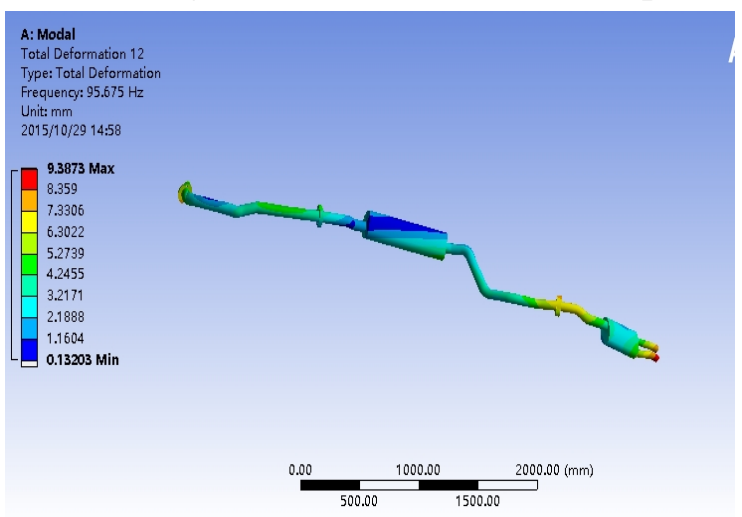

Figure 7 The $12^{\text {th }}$ mode of restrained modal without optimization 


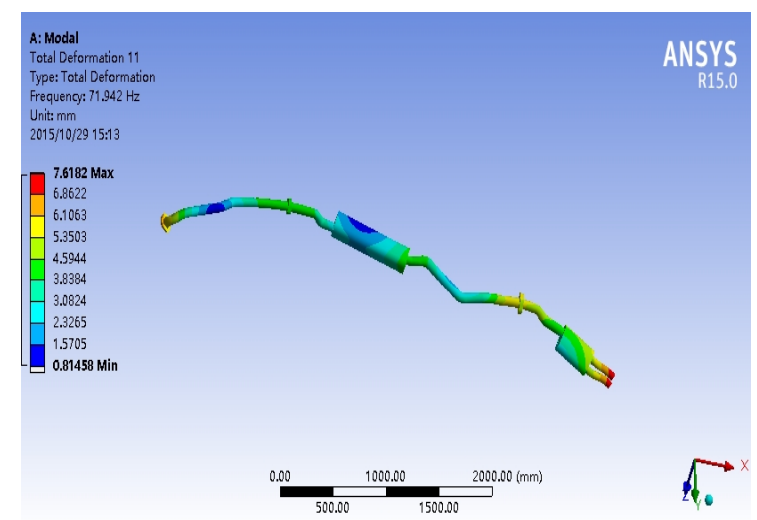

Figure 8 The $11^{\text {th }}$ mode of restrained modal after optimization

\section{The statics and dynamics analysis of exhaust system}

The reaction force of the lifting lug is extracted from the Ansys, and the amount of the forces of the original model lifting ear 1 to 5 is $28.978 \mathrm{~N}, 57.106 \mathrm{~N}, 60.311 \mathrm{~N}, 26.469 \mathrm{~N}, 45.992 \mathrm{~N}$.After the suspension point position optimization of the hanging ear, the forces of NO1 to 5 ears are $30.125 \mathrm{~N}$, $34.354 \mathrm{~N}, 25.761 \mathrm{~N}, 39.051 \mathrm{~N}, 37.12 \mathrm{~N}$, we can know that in the original model, reaction forces are in a large difference, the pre-load distribution is not uniform, which is needed to optimize the layout. After the suspension point rearrangement of the suspension, the maximum difference is $8.926 \mathrm{~N}$ among the ears, and the distribution is more uniform. The constraint reaction of the lifting lug is calculated as follows, as shown in Figure 10, before the optimization, among the 1-5 hanging ears, the fourth lifting ear dynamic reaction force peak is $51.3 \mathrm{~N}$, and before $20 \mathrm{~Hz}$ the dynamic force of the ear is greater than $10 \mathrm{~N}$.

This process is from the start the idle speed, the impact of the vibration characteristics of the vehicle is obvious, the maximum value of the anti-force is near the $20 \mathrm{~Hz}$, the idle frequency is getting very close, but with the modal frequency lifting, the anti-force amplitude are reduced to $10 \mathrm{~N}$. In addition, the reaction force of the curve has many peaks and the curve is not smooth. When the position is optimized, the peak value of the dynamic reaction force at the fourth hanging ear is $49.1 \mathrm{~N}$, and all the final reaction forces are reduced to $5 \mathrm{~N}$, and the reaction force curve becomes more uniform.

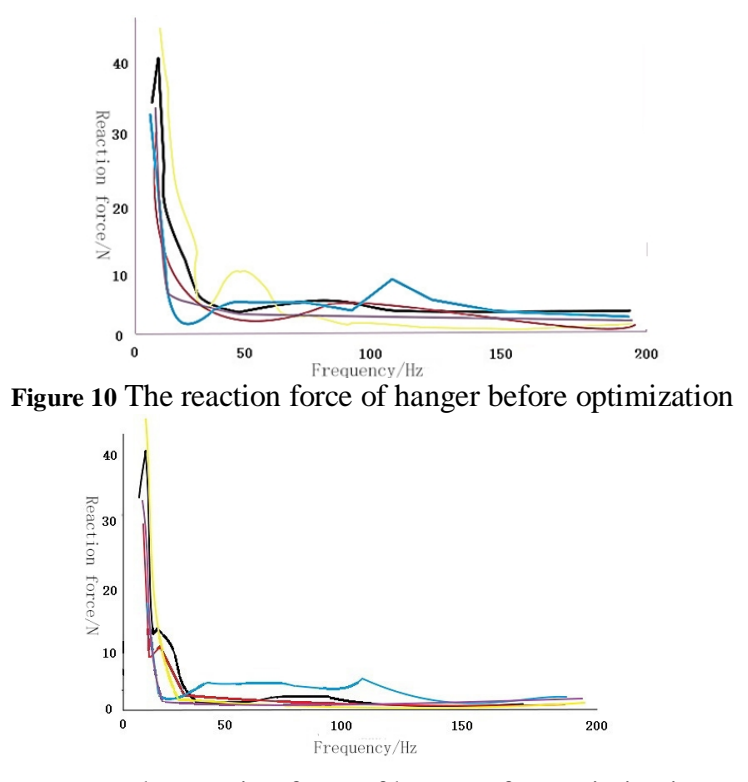

Figure 11 The reaction force of hanger after optimization 


\section{Conclusion}

First of all, in this article, mainly the vibration characteristics were analyzed with modal analysis method. And the using modal synthesis node method to do the hanger point position optimization, after the constrained modal analysis, by comparing the curves of reaction forces before and after optimization, verifying the move to improve some exhaust system NVH performance is effective.

\section{References}

[1].Xianyang XU, Modal Analysis Optimization of Vibration of the Vehicle System,

[2].Pang Jian, Chen Gang, Hehua, VehicleNoise and Vibration Control Theory and Application [M]. Beijing: Beijing Science and Technology University Press (2006).

[3].SAIC 1.5T vehicle exhaust system technical documentation, Shanghai, SAICMOTOR (2014)

[4].Li Zhen, Peng Jianghua, Yang Guoxiong, Based on the Hypermesh secondary development of the exhaust system analysis, Altair 2009 Hyperworks technology conference proceedings. (2009)

[5].Zhang Xiulu, Hanger Locatoins' Design and Structural Optimization of the Vehicle Exhaust System, Jilin, Jilin University, School of mechanical science and engineering. (2014)

[6].Li Yancai, The modal analysis of exhaust system and analysis of hanger position based on NASTRAN, Southeast(Fujian) Automobile Industry, The technology of machine and electronics. (2014)

[7].Jiang Miaomiao, The optimization on vibration of some passenger car[D],Guangzhou, South China University of Technology,2015.6

[8].Dong Zhixin, Study on Structural Performance and Optimization of Automobile Exhaust System[D], Guangzhou, South China University of Technology,2014.6

[9].Liu Ming, Vibration Analysis of Exhaust System and its optimization[D],Nanjing,Nanjing University of Aeronautics and Astronautics,School of Thermal an

[10]. d Power Engineering,2009.12 